\title{
Long-term effects of maternal punishment on the behavior of monkeys
}

\author{
G. D. MITCHELL, G. L. ARLING AND G. W. MøLLER 1.2 \\ PRIMATE LABORATORY, UNIVERSITY OF WISCONSIN
}

Adolescent monkeys having punitive mothers for the first three months of life display more aggression and less social exploration than adolescent monkeys having non-punitive mothers.

Social deprivation in rhesus monkeys sometimes produces brutal or excessively punitive maternal behavior (Harlow, Harlow, Dodsworth, \& Arling, 1966). The development of the offspring of such punitive mothers has been studied in detail by Seay, Alexander, \& Harlow (1964) and by Arling \& Harlow (1967). Arling \& Harlow (1967) found that the infants reared by brutal motherless mothers displayed high levels of peer directed aggression before one year of age. Although Seay et al (1964) concluded that these infants were not abnormally aggressive prior to one year of age, Sackett (1965) tested two of the Seay et al (1964) infants at three years of age and found that these animals, too, showed excessive physical aggression.

The present study compared the adolescent behaviors of the infants of punitive mothers with the adolescent behaviors of infants of non-punitive mothers and was specifically designed to test the hypothesis that maternal punishment leads to an increase in adolescent aggression. The mothers were selected for the amount of punishment they administered without regard to whether they were jungle-reared or lab-reared.

\section{Subjects}

The early records of 16 male and 16 female adolescent rhesus monkeys, who had been reared at the University of Wisconsin, were searched for data bearing on brutality, punitiveness, or rejection by their mothers. Of the 32 mothers, 28 were jungled-reared and four were lab-reared. The Ss were rank ordered according to how frequently their mothers rejected, bit, aggressed, or withdrew from them during the first three months of life. Each of the four punitive behaviors were ranked separately. The infants who received the 16 highest mean ranks (the eight highest ranked males and the eight highest ranked females) were classified as the high punished group (HP) and the other 16 as the low punished group (LP).

All 32 Ss had been reared for eight months with their mothers in playpens previously described by Hansen (1966). The maternal rankings are based on data accumulated during the first three months in three mother-infant interaction studies conducted by Alexander (1966), Arling (1966), and Griffin (1966). The modified Hansen scoring system (1966) was used by all three of the above investigators. In this standard system, mother-infant behaviors are measured in terms of the occurrence of a particular behavior during successive $15 \mathrm{sec}$ intervals of $15 \mathrm{~min}$ test sessions. While the original rearing conditions imposed upon these mother-infant pairs varied between the three basic experiments above, all 32 infants lived with their mothers in the playpens for $24 \mathrm{~h}$ a day throughout the eight months. At the end of this time, the Ss were separated from their mothers and housed in groups of from four to six animals.

Tests for long-term effects of punitiveness were conducted when the Ss were between 15 and 39 months of age, an average of 20 months following maternal separation. Two stimulus animals, one adult (age five and one-half years) and one infant (age one month). were selected to maximize the differences between the two groups (cf., Mitchell, Raymond, Ruppenthal, \& Harlow, 1966). The adult, an extremely aggressive female total social isolate, was selected to educe normal fear or inappropriate aggression from the Ss. The infant, a male, was chosen to elicit a minimum of fear and unprovoked aggression.

\section{Apparafus}

The 32 Ss were tested in a $6 \mathrm{ft} \times 2 \mathrm{ft} \times 3 \mathrm{ft}$ cage with a door (16 $x$ (1) 9 in.) at one end through which the Ss entered.

Procedure

All of the Ss were given a $2 \mathrm{~h}$ adaptation period in the apparatus prior to four test sessions with the infant. The order of testing for the 128 infant sessions was balanced for age, sex, rearing, and $\mathbf{E}$. The adult stimulus animal was adapted for $2 \mathrm{~h}$ and the $32 \mathrm{Ss}$ were then paired four times with her. No $S$ was tested more than once a day or more than twice a week. The $5 \mathrm{~min}$ session began when $\mathrm{S}$ entered the test cage. The frequencles of five behaviors (physical aggression, social threat, redirected threat, stereotyped movements, and social exploration) were recorded by a manually operated counter system. The behaviors of the stimulus animals were not recorded. Each of two Es tested $16 \mathrm{Ss}$ which were matched for age, sex, and early maternal punitiveness. Similarly, every HP was matched with an LP for sex, age, and rearing, and a two-tailed Wilcoxon test (Slegel, 1956) was used for both the $E$ and group effects. An alpha level of .05 was used.

Results

There were no significant $E$ effects on any of the five behaviors scored, but several group differences were statistically reliable. The HPs $(2.00)^{3}$ physically 
aggressed the stimulus animals significantly more often than the LPS (0.25), and the difference in mean frequency of social threat (HP 3.63, LP 1.56), though not significant, was in the same direction. Despite these differences in socially directed hostility, the total amount of hostility displayed by the two groups was about equal because the LPs redirected a large percentage of hostility $(87.2 \%)$ in the form of $E$ directed threats, yawns, and cage shakes, while the HPs redirected only $43.3 \%$. There were significantiy more repetitive stereotyped movements, such as pacing, jumping, and flipping, among the HP females (64.38) than among the LP females (17.50), but this difference was not evident in the males. The mean frequency of social exploration (manual, oral, or visual exploration while maintaining physical contact with the stimulus animal) was significantly lower in the HPs (3.63) than in the LPs (10.81).

Discussion

Arling \& Harlow (1967) presented evidence that infants reared by indifferent or abusive mothers displayed high levels of aggression. The present data indicate that even jungle-reared mothers can administer a level of punishment to their infants which leads to detectable increases in adolescent aggression. The overall level of hostility does not seem to be altered by early maternal punishment. However, while the infants of non-punitive mothers are able to redirect most of this hostility in the form of yawns and $E$ directed threats, the HPs are more directly and physically aggressive. The difference in physical aggression between the two groups cannot be attributed to physical size, since the mean weights of the two groups (HP $3.03 \mathrm{~kg}$, LP $3.25 \mathrm{~kg}$ ) are not significantly different.

The hypothesis that maternal punishment leads to an increase in direct adolescent aggression is strongly supported by the present data. Since aggression matures relatively late and continues to increase up to six years of age in the rhesus monkey (Cross \& Harlow, 1965), it is not surprising that the differences reported here became even more marked at a later age. We witnessed some dramatic instances of still more severe aggression in the HPs after the present experiment had ended. The two most highly punished males of the present HPs severely aggressed a female cagemate and bit off several fingers. After this incident had occurred, these males were removed from the group living cage but were mistakenly returned for one weekend, during which they killed another female.

\section{References}

Alexander, B. K. The effects of early peer deprivation on juvenile behavior of rhesus monkeys. Unpublished doctoral dissertation, University of Wisconsin, 1966.

Arling, G. L. Effects of social deprivation on maternal behavior of rhesus monkeys. Unpublished Masters Thesis, University of Wisconsin, 1966.

Arling, G. L., \& Harlow, H. F. Effects of social deprivation on maternal behavior of thesus monkeys. J. comp. physiol. Psychol. (in press)

Cross, H. A., \& Harlow, H. F. Prolonged and progressive effects of partial isolation on the behavior of macaque monkeys. J. exp. Res. Pers., 1965, 1, 39-49.

Griffin, G. A. The effects of multiple mothering on the infant-mother and infant-infant affectional systems. Unpublished doctoral dissertation, University of Wisconsin, 1966.

Hansen, E. W. The development of maternal and infant behavior in the rhesus monkey. Behaviour, 1966, 27, 107-149.

Harlow, H. F., Harlow, M. K., Dodsworth, R. O., \& Arling, G. L. Maternal behavior of rhesus monkeys deprived of mothering and peer associations in infancy. Proc. Amer. Phil. Soc., 1966, 110 , $58-66$.

Mitchell, G. D., Raymond, R. J., Ruppenthal, G. C., \& Harlow, H. F. Long-term effects of total social isolation upon the behavior of rhesus monkeys. Psychol. Rep., 1966, 18, 567-580.

Sackett, G. P. Effects of rearing conditions upon the behavior of rhesus monkeys (Macaca mulatta). Child Develpm., 1965, 36, 855-868.

Seay, B. M., Alexander, B. K., \& Harlow, H. F. Maternal behavior of socially deprived thesus monkeys. J. abnorm. soc. Psychol., $1964,69,345-354$.

Siegel, S. Nonparametric statistics for the behavioral sciences. New York: McGraw-Hill, 1956.

\section{Notes}

1. This research was supported by National Institute of Health Grant (MH-11894) to Dr. Harry F. Harlow.

2. G. D. Mitchell is presently at the National Center for Primate Biology, Davis, California; G. W. Moller is at the Dept. of Behavior, The Zoological Garden, Copenhagen F, Denmark; and G. L. Arling is at the University of Wisconsin Primate Laboratory.

3. The numbers in parentheses following group abbreviations refer to mean frequencies across both trials and stimulus animals. 